\section{The Costs and Benefits of "Open Access"}

\section{Philip G. Altbach}

Philip G. Altbach is Monan University Professor and director of the Center for International Higher Education at Boston College. He served as editor of the Comparative Education Review and the Review of Higher Education.

The Harvard Faculty of Arts and Sciences recently joined the 1 "open access" movement, urging its professors to post their research on an open access Harvard Web site (while adding an "opt out" choice for professors who wish to submit their work to traditional journals). In this way, Harvard professors have joined a growing chorus of critics of the traditional journal publishing system by offering its research and analysis without cost to all readers through the Internet. The basic argument claims that knowledge should be free to everyone and that the Internet permits easy worldwide access. This philosophical commitment is linked to revulsion against the increasingly monopolistic and predatory practices of the multinational journal publishers.

For Harvard, the decision is relatively cost free. Its institutional prestige and the prominence of many of its faculty will ensure that scholars gravitate to its Web site and that the work of its researchers will not be ignored. Similarly, the Massachusetts Institute of Technology initiated its open courseware program, which brought most of MIT's courses to the Internet to be accessed by all, being praised as a major contribution to knowledge-as indeed it is.

But a significant downside exists. This movement may well ensure that scholars prominent in the world of knowledge remain a dominant force, while recognition of the work of others may prove to be more difficult. Open access after all does ensure that knowledge will be equally used. This practice simply places material on the Internet to join the exponentially expanding universe of information. The problem, of course, is one of selection. How does a user of research select the best and most relevant material from the vast array of information currently available?

\section{The Traditional System}

The traditional scholarly journal provides a means of selection. The peer-review system, however imperfect it is, does a reasonably good job of vetting research and scholarship and publishing what is considered by thoughtful experts to be the most effective approach. Journal editors to some extent control the flow of manuscripts, and recognized experts anonymously evaluate them. The most deserving articles are then published. The journals themselves are ranked, customarily by the informal subcultures of the disciplines and, more recently, by the much criticized "impact factors" and other bibliometric measures.

New journals, generally part of the traditional system, were established to reflect new scientific and scholarly research, academic and societal needs, and interdisciplinary trends that have enlivened scholarship in recent decades. Some of these journals have gained prominence, while others have not. The key contribution of this system is that it provides a reasonably effective means of peer review and selection. Users are given an easy-sometimes too easy-way of selecting what is worthwhile knowledge and deciding what might best be ignored.

\section{An Out-of-Control System}

Unfortunately, the traditional journal system has come under a multifaceted attack in recent years. The most important reality is that the system has become commercialized. Major multinational publishers, such as Springer and Elsevier, have purchased many existing journals and have dramatically increased subscription prices. Most affected are journals in the biomedical and natural sciences but in other fields as well. This trend has led to dramatic price increases that have caused problems for academic libraries, the traditional purchasers of journals. These publishers and many other smaller, for-profit, firms have created new journals, in part to serve the needs of an expanding knowledge base but also simply to create more profit-making titles. In addition, the big producers are increasingly "bundling" their journals and insisting that libraries purchase large numbers of them through electronic networksthe more journals, the higher the price. A contributing factor includes the growing competitiveness of academe itself and the need of academics to publish more to obtain promotion and salary increases.

The basic argument claims that knowledge should be free to everyone and that the Internet permits easy worldwide access.

The academic accountability movement has strengthened the traditional journal system, through the positive impact of the increasingly important citation analyses and impact factors. While these measures are far from perfect and tend to disadvantage scholarship from developing countries and other peripheral systems, they are widely used to determine academic promotions, university and departmental rankings, and for other purposes in a competitive academic system. Research assessment exercises, such as the one in England, count heavily on impact factors. Universities in China, Norway, and Israel, among many others, pay their professors to publish in internationally recognized journals. It is worth noting that the citation analyses are now in the hands of for-profit companies.

The corporatization and overexpansion of journals have created the environment for the open access movement. 
Academics, librarians, and some administrators think they have found a way around the increasingly expensive and monopolistic journal system-bypassing them altogether.

\section{Problems}

There are several problems with open access. Essentially, peer review is eliminated and all knowledge becomes equal. The current outlook implies "let the buyer beware," but most customers lack the expertise to make good choices. There is no quality control on the Internet, from a Wikipedia article to an essay by a distinguished researcher. In a strange way, open access may benefit those already at the top of the knowledge system. A Harvard open access Web site is likely to attract readers simply because of its world-class name. A less well-known institution in a developing country, for example, would likely gain less attention, not to mention a posting by a little-known scholar at a peripheral institution. While the traditional jour-

\section{The academic accountability movement has} strengthened the traditional journal system.

nals also tend to privilege scholars working at top institutions, at least the peer-review system gave some chance for publication in recognized journals. Essentially, open access means there is no objective way of measuring the quality of research without each individual evaluating it. If the traditional journals and their peer-review systems are no longer operating, there is anarchy in the evaluation of scholarship. Counting the number of times an article is accessed is possible, but it is quite likely that the randomness of a Google search will skew such evaluations. Researchers will have no accurate way of assessing quality in scholarly publication.

\section{A WAY FORWARD?}

The old practice may well be the best, although flawed, way of communicating research. Scholarly journals owned by academic societies or universities or other nonprofit publishers provide a filter and peer review. The more innovative nonprofit publishers, such as the Johns Hopkins University Press and its Project MUSE, creatively used the Internet for distribution. Prices were not exorbitant. The recent decision by the American Anthropological Association to lease their journals to a for-profit publisher, which has already raised prices, seems like a move in a negative direction. Without question, the proliferation of knowledge and the increasing complexity of dissemination through the Internet has creased unprecedented strains on the knowledge communication system. Open access, while it seems like an easy panacea, has problems that deserve careful consideration.

(This article appeared in Times Higher Education [London] on June 5,2008 ).

\section{Teaching in English on the Rise in European Education BERND WÄCHTER}

Bernd Wächter is the Director of the Academic Cooperation Association. Email: bernd.waechter@aca-secretariat.be.

$\mathrm{T}$ he latest UNESCO data cited 2.7 million international students worldwide in 2005 , up from I.8 million in 2000 and 600,000 in I975. The figures are expected to rise fast in the coming years. While a fierce competition has set in over these students, non-English-speaking destinations are often seen as disadvantaged in this sector. The linguistic handicap is one of the reasons why continental European countries started, some Io years ago, to introduce instruction in English. In 2002, the Academic Cooperation Association, a Brussels-based European association specialized in the internationalization of higher education, produced the first ever empirical study on this phenomenon. Six years later the organization has now come out with a follow-up study (Bernd Wächter and Friedhelm Maiworm. English-Taught Programmes in European Higher Education: The Picture in 2007. Bonn: Lemmens, 2008). This article presents the key findings from the original publication.

\section{Strong Growth, Uneven Distribution}

The study is based on surveys of 2,200 higher education institutions in 27 European countries where English is not the domestic language of instruction. It identified about 2,400 English-medium programs in the 38 percent of responding institutions. This finding translates into a threefold increase since the 2002 surveys. Despite this, the English-medium offer still represents only a modest share of the average European program provision.

It is important to note that English-medium provision unevenly extends across Europe. Nearly one-third of all identified programs are offered by institutions in the Netherlands, the uncontested European leader in this form of education. Germany, the second provider in absolute numbers, occupies only a modest middle-rank position. The Nordic countries all score at high levels. Higher education institutions in southern Europe, on the other hand, offer very few programs in English. In institutional terms, it is the PhD-awarding, multidisciplinary (comprehensive) universities with large enrollments rather than the smaller, college-type institutions that offer most English-medium programs. Interestingly, there is no clear correlation between the number of these programs and the number of international students at an institution. Institutions with a modest proportion of international students-above all in countries with languages less often spoken, internationally-appear to use English-medium programs as a means of "countersteering." They introduce these 